\title{
Modelling the increased frequency of extreme sea levels in the Ganges-Brahmaputra-Meghna delta due to sea level rise and other effects of climate change
}

\author{
S. Kay, ${ }^{a}$ J. Caesar, ${ }^{b}$ J. Wolf, ${ }^{c}$ L. Bricheno, ${ }^{c}$ R.J. Nicholls ${ }^{d}$ A.K.M. Saiful Islam, ${ }^{e}$ A. Haque, ${ }^{e}$, A. Pardaens ${ }^{b}$ and \\ Jason Lowe ${ }^{b}$
}

Coastal flooding due to storm surge and high tides is a serious risk for inhabitants of the Ganges-Brahmaputra-Meghna (GBM) delta, as much of the land is close to sea level. Climate change could lead to large areas of land being subject to increased flooding, salinization and ultimate abandonment in both West Bengal, India, and Bangladesh. IPCC $5^{\text {th }}$ assessment modelling of sea level rise and estimates of subsidence rates from the EU IMPACT2C project suggest that sea level in the GBM delta region may rise by 0.63 to $0.88 \mathrm{~m}$ by 2090 , with some studies suggesting this could be up to $0.5 \mathrm{~m}$ higher if potential substantial melting of the West Antarctic ice sheet is included. These sea level rise scenarios lead to increased frequency of high water coastal events. Any effect of climate change on the frequency and severity of storms can also have an effect on extreme sea levels. A shelf-sea model of the Bay of Bengal has been used to investigate how the combined effect of sea level rise and changes in other environmental conditions under climate change may alter the frequency of extreme sea level events for the period 1971 to 2099. The model was forced using atmospheric and oceanic boundary conditions derived from climate model projections and the future scenario increase in sea level was applied at its ocean boundary. The model results show an increased likelihood of extreme sea level events through the 21 st century, with the frequency of events increasing greatly in the second half of the century: water levels that occurred at decadal time intervals under present-day model conditions occurred in most years by the middle of the $21^{\text {st }}$ century and 3-15 times per year by 2100 . The heights of the most extreme events tend to increase more in the first half of the century than the second. The modelled scenarios provide a case study of how sea level rise and other effects of climate change may combine to produce a greatly increased threat to life and property in the GBM delta by the end of this century.

\section{Introduction}

The Ganges-Brahmaputra-Meghna (GBM) delta has long been recognised as being highly vulnerable to sea-level rise, as shown by Milliman et al. ${ }^{1}$ and Warrick et al. ${ }^{2}$, among others. These analyses also recognised the potential role of subsidence in enhancing these global effects. Large areas of land could be subject to increased flooding, salinization and ultimate abandonment in both West Bengal, India, and Bangladesh. An early estimate suggested that Bangladesh could lose up to $34 \%$ of currently habitable land by $2100^{1}$. This in turn has been linked to the potential displacement of millions of people from their homes; in a global assessment of deltas, Ericson et $\mathrm{al}^{3}$ ranked the GBM delta as one of the most vulnerable, just based on extrapolating current trends.

Recent projections from the Intergovernmental Panel on Climate Change (IPCC) ${ }^{4}$ suggest that sea level in the northern Bay of Bengal may rise by 0.1-0.3 m by 2050 and by $0.3-0.6 \mathrm{~m}$ by 2100 , and possibly more - see the next section for a fuller discussion. These values are due to climate change alone, but subsidence will increase the rise in sea level experienced on the ground; this issue was raised by Milliman et a.1. ${ }^{1}$ in 1989, when little data was available to quantify the effect, and studies since 2000 have confirmed that the coastal areas of the GBM delta are undergoing land subsidence ${ }^{5,6}$. Syvitski et al. ${ }^{7}$ argued that the entire GBM delta is sinking at an alarming rate.

Rising sea level has been observed at coastal monitoring sites in Bangladesh. The observed trend in sea level rise relative to local land level at Hiron Point, Char Changa and Cox's Bazar was found to be $+4.0 \mathrm{~mm} / \mathrm{yr}$, $+6.0 \mathrm{~mm} / \mathrm{yr}$ and $+7.8 \mathrm{~mm} / \mathrm{yr}$ respectively using tidal gauge records of 22 years from 1977 to $1998^{8}$. Tide gauge data from the wider Bay of Bengal show sea level rise going back more than 50 years ${ }^{9}$ These relative sea level rise values are highly site-specific, since they include locally-varying subsidence $e^{10,5,11}$ and tidal amplification or dampening caused by change in land shape, local coastline shape and water depth. These local changes can result from natural accretion and formation of new funnel-shaped chars and islands ${ }^{7,12}$ and also by human interventions such as construction of cross-dams to trap sediment.

The assessment of the combined impact of sea level rise (SLR) and subsidence is hindered by limited data both on the physical state of the delta and the people who live on the delta and how they make their livelihoods. The ESPA Deltas project aims to assess the contribution of ecosystem services to poverty alleviation in the GBM delta, as climate change develops over the next 50-100 years. Within ESPA Deltas, a hydrodynamic and lower trophic level model of the Bay of Bengal was used to model marine primary production for fisheries projections and to generate boundary condition data for higher resolution models of the delta. The model outputs include a 129-year time 
series of hourly sea surface elevations, for three alternative sets of climate conditions. Here we present analysis of these time series, assessing the changing incidence of high water events to 2100. The model's resolution is not high enough to allow us to make detailed projections about changing sea levels at each location on this complex shoreline. Nonetheless, we believe the outputs can provide a useful contribution to understanding how sea level rise may be manifest on the Bangladesh portion of the GBM delta and its possible effect on the frequency and severity of extreme sea level events.

At least five factors work together to determine the height of the sea at any given coastal location and time:

1. background mean sea level: due to global and regional effects of climate warming and to subsidence

2. weather conditions: coastal flooding in Bangladesh is often associated with cyclone-induced storm surges or with onshore winds that persist for a number of days

3. the tidal cycle

4. the local shape and depth of the sea bed, which is affected by subsidence and by the morphodynamic movement of sediment

5. local river flow volume.

In this paper we describe results from a modelling study of coastal Bangladesh which includes the first three of these factors and has a coarse-scale treatment of the fifth. A $0.1^{\circ}$ (approx. $11 \mathrm{~km}$ ) resolution hydrodynamic model of the coastal region of the Bay of Bengal, based on the GCOMS model framework $^{13}$, was run for three different climate scenarios for the $21^{\text {st }}$ century. These three climate scenarios are all for a medium Business-As-Usual greenhouse gas forcing scenario (the SRES A1B scenario) but differ in their atmospheric forcing conditions, with these being obtained from alternative atmospheric model projections. The atmospheric projections were downscaled from the global scale using a regional atmospheric climate model (RCM). The climate scenarios are described in more detail in Caesar et al. (2015) ${ }^{14}$. Sea level rise within the region was modelled by applying a time-varying increase in height at the open ocean boundary at each model time step. The size of the increase varied in time and was set based on current projections by the IPCC for the northern Bay of Bengal 4 .

Wind and pressure forcing, together with rainfall run-off and modelled tides, provide some indication of the shorter time scale variability of sea level including extreme events. The modelled results give a continuous time series of sea surface height at hourly time intervals and at each $0.1^{\circ}$ model gridpoint in the region of the GBM delta, for the time period 1971 to 2099. This dataset thus enables an estimate of the potential increase in extreme sea level events. Previous work has looked at the impact of sea level rise on flood risk for different regions around the globe, e.g. Kopp et al. ${ }^{15}$, or used some sample conditions of possible future sea level and climate, e.g. Karim and Mimura ${ }^{16}$. This is the first modelling work to investigate the combined effects of sea level rise and other changes in environmental conditions associatd with climate change for the GBM region on a century time-scale using the IPCC 2013 projections of sea level rise ${ }^{4}$.

The next section summarises the methods use to build sea level forcing into the model, including discussion of the data used, and includes a comparison of the three climate scenarios used. Section 3 describes the model set-up and validation. Section 4 presents and discusses results from the model for three climate scenarios. The final section summarises the conclusions from these results.

\section{Methods and data for modelling sea level}

Sea level rise at the GBM delta was modelled using a POLCOMS model of the Bay of Bengal. POLCOMS, the Proudman Oceanographic Laboratory Coastal Ocean Modelling System $^{17}$, is a three-dimensional baroclinic hydrodynamic model designed for studying coastal and shelf seas. In common with many numerical ocean models, it uses the 'Boussinesq approximation' for density changes, with the effect that volume but not mass is conserved within the model. The effect of sea level rise can be modelled by adding a correction to the sea surface elevation to adjust for steric effects missed by the Boussinesq approximation $^{18}$. In this model the adjustment is made at the open ocean boundary, where an elevation is imposed that includes change in the background mean sea level, tidal forcing and the effect of ocean dynamics. The following sections describe the data used for each of these sources of forcing,

\section{Background sea level rise}

In the work presented here, sea level rise for the region was based on projections for Haldia in West Bengal, India $\left(22.0^{\circ} \mathrm{N}\right.$, $88.1^{\circ} \mathrm{E}$ ), produced for the Fifth Assessment Report of the Intergovernmental Panel on Climate Change, IPCC (AR5) ${ }^{4}$. Global mean sea level rise depends on two main physical processes: changes in boundary fluxes of water, primarily from net melt of ice sheet and glaciers, and the steric effect of thermal expansion of sea water ${ }^{18}$ under global warming. Ocean thermal expansion and glacier melting have been the dominant contributors to 20th century global mean sea level rise, such that thermal expansion and glaciers (excluding Antarctic glaciers peripheral to the ice sheet) are estimated to explain around $75 \%$ of the observed rise ${ }^{4}$. However, the contribution of the Greenland and Antarctic ice sheets has notably increased since the early 1990s and is an important component of future projections. Natural and human-induced land water storage changes have made only a small contribution to global SLR, although the rate of ground-water depletion has increased and now exceeds the rate of reservoir impoundment.

On a regional basis the time mean sea level change can vary sizeably from the global mean value, due to local differences in 
density change from both temperature and salinity effects, and to changes in circulation. Additionally, melting ice does not contribute uniformly, with sea level fingerprints taking account of, for instance, changes in the gravity field as water is redistributed ${ }^{4}$.

The geographically varying projections in the AR5 were created using an ensemble of 21 general circulation models from the Coupled Model Intercomparison Project Phase 5 (CMIP5 ${ }^{19,13}$ ), together with state of the art modelling of glaciers and ice sheets. The sea level rise projections include thermal expansion, the effect of atmospheric loading, land-ice melt (including estimates of ice sheet rapid dynamic contributions derived from the literature), glacial isostatic adjustment and terrestrial water storage changes.

The atmosphere and ocean data required to run the Bay of Bengal model were created using the widely used SRES A1B greenhouse gas scenario ${ }^{20}$. However, regional sea level rise projections under the up-to-date AR5 methodology were not readily available for this scenario. Therefore AR5 projections for this region were adjusted to give representative median local A1B values using a pattern-scaling approach ${ }^{21}$ : the RCP4.5 values were multiplied by 1.117 , the ratio of their global-mean median projections under RCP4.5 and A1B (Fig. 1). This gave an approximate A1B sea level rise of $0.54 \mathrm{~m}$ by 2100 for this location. A smoothed version of the observed data and A1B derived projection were used in the modelling described here. Note that the observed data in Fig. 1 shows more variability than the projections because the latter come from a multi-model ensemble. None of this variability was included in the current work, instead variability resulted from forcing by climate projections, tides and river flow as described below.

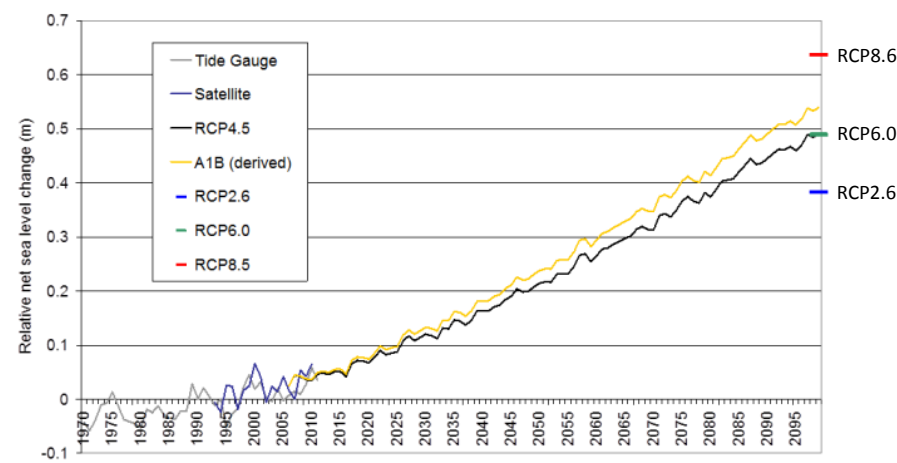

Fig. 1. Sea level rise median projections for Haldia, West Bengal, relative to 1986 2005, using data from IPCC AR5 Fig 13.23 and showing our derived projection for A1B. Tide gauge and satellite values are shown up to 2010 , values from a multimodel ensemble for 2005 onwards. The black line (RCP4.5) shows IPCC AR5 values, the yellow line (A1B) shows data derived from this by multiplying by the global A1B:RCP4.5 ratio. Alternative scenarios RCP2.6, RCP6.0 and RCP8.5 are shown for 2100 .
The IPCC AR5 report also gives projections for three other greenhouse gas scenarios: the lower emission RCP2.6 scenario, which assumes substantial mitigation, and the higher emission RCP6.0 and RCP8.5 scenarios. The median projections at 2100 for Haldia under these scenarios are $0.38 \mathrm{~m}, 0.48 \mathrm{~m}$ and $0.63 \mathrm{~m}$ respectively (Fig. 1). AR5 notes that a collapse of the marinebased sectors of the Antarctic ice sheet, if initiated, could potentially add up to a further several tenths of a metre of sea level rise, independent of scenario; Levermann et al. ${ }^{22}$ estimate that this could be around $0.5 \mathrm{~m}$. This additional amount, when combined with the upper limit of the AR5 highest-emissionscenario (RCP8.5) likely range, gives a value of sea level rise by 2100 of around $1.5 \mathrm{~m}$, not including potential local variations or subsidence. Another recent work ${ }^{23}$ estimates $1.8 \mathrm{~m}$ as the upper limit of global mean sea level rise by 2100 . The work presented here was based on the most likely value for the A1B scenario, without the additional ice sheet contribution, but it should be borne in mind that levels up to $0.8 \mathrm{~m}$ higher are consistent with the studies cited above.

The effect of subsidence was not included in the model runs, since data was only available for the delta region and this is unlikely to represent the rate of subsidence across the Bay as a whole. Subsidence has been added to the results presented here, for years after 2006 where the sea level was based on projection not observed values. A uniform subsidence rate of $2.5 \mathrm{~mm} / \mathrm{yr}$ relative to the year 2000 was used, based on an assessment of all the available data available in the GBM delta ${ }^{24}$. This additive approach omits any nonlinear effects caused by the extra depth due to subsidence, but since the maximum size of the subsidence is only $2.5 \%$ of the minimum water depth (i.e. $0.25 \mathrm{~m}$ in $10 \mathrm{~m}$ after 100 years) it is a reasonable approximation.

The century-long time-scale of the modelling required mean sea level to be adjusted at regular intervals, rather than with a oneoff change in bathymetry as is sometimes used in hydrodynamic models (Fig. 2). Here sea level rise was modelled by adding an increment to the sea surface elevation boundary condition every 24 hours, based on the A1B projection. The boundary elevation is interpolated to the 20 second model timestep and model processes rapidly propagate the increased surface elevation through the rest of the domain. The new sea depth is fed forward to the next time step, so total water depth in the model is altered without needing to modify the model bathymetry. This method effectively combines the high frequency tidal and meteorologial forcing with the slower change in mean sea-level. 


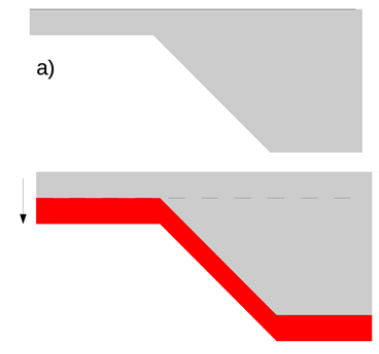

a) Statically deepening the water. This can only be done before running the model, and is applied in a discontinuous manner by deepening bathymetry once.

Fig. 2. Schematic diagram representing how sea-level rise can be included in a hydrodynamic model. (a) and (b) show two alternative projections; method (b) is used in the current work.

\section{Modelling of tides}

Tidal forcing is built into POLCOMS through forcing at the open ocean boundary. 8 harmonic components were used: Q1, $\mathrm{O} 1, \mathrm{P} 1, \mathrm{~K} 1, \mathrm{~N} 2, \mathrm{M} 2, \mathrm{~S} 2$ and $\mathrm{K} 2$. Elevation and current boundary conditions were derived from a tidal model $\left(\mathrm{TPXO}^{25}\right)$, and nodal factors and date corrections were applied within the model. The tidal forcing was kept constant: it was assumed that tides in the open ocean will not change during the $21^{\text {st }}$ century.

\section{Atmospheric forcing and ocean boundary conditions}

Ocean and atmospheric boundary condition data were downscaled from global projections by versions of the the atmosphere-ocean coupled global climate model, HadCM3 ${ }^{26}$, under the SRES A1B scenario. Three members of a 17-member perturbed physics ensemble (PPE) ${ }^{27,28,29}$ were used, where these were selected to give a range of climate outcomes for the Bangladesh area. In the ESPA Deltas projct these have been used as three alternative scenarios of climate change, denoted as the Q0, Q8 and Q16 scenarios after their ensemble member names ${ }^{14}$. Q0 represents the unperturbed version of the model and Q8 and Q16 represent model versions which have increasingly higher global climate sensitivity, but none should be considered the most plausible and neither should they be considered as equally likely. The atmospheric forcings over the Bay of Bengal were downscaled using consistent versions of the atmospheric regional climate model HadRM $3 \mathrm{P}^{30}$, which is itself forced using downscaled outputs from HadCM3.

HadCM3 uses the Boussinesq approximation and it also has a rigid lid for the ocean model component, which means that sea surface elevation is not estimated directly by the model and is instead derived from the surface pressure. These pressurederived elevations include information about meteorologicallyforced ocean dynamics, but not global mean sea level rise. Boundary conditions for the Bay of Bengal model included the sea surface elevation from HadCM3, interpolated from monthly data at $1.25^{\circ}$ resolution, and mean sea level rise as described above. Boundary condition data for temperature, salinity and current speeds were also taken from HadCM3.

For validation purposes, the model was run for 1991-2009 using forcing from reanalysis data, ERA Interim ${ }^{31}$ for the atmospheric data and GLORYS ${ }^{32}$ for the ocean. No sea level rise was imposed and the tidal forcing was the same as the runs driven by climate model data.

\section{Rivers}

Inputs of freshwater at river mouths in the GBM delta area were provided using outputs from a hydrological model of the river basins ${ }^{33,34}$ : these were created using the same HadRM3P Q0, Q8 and Q16 climate forcing data as the Bay of Bengal model. The GBM rivers provide $40 \%$ of the modelled freshwater flow into the entire domain and dominate in the delta area. For rivers outside the delta no hydrological model was available and the annual mean discharge was taken from a global dataset of climatological runoff values ${ }^{35}$ with daily values set by imposing a seasonal factor based on observed flows taken from the database of Dai and Trenberth ${ }^{36}$. For these rivers the flow did not vary with the year or climate scenario.

\section{Comparison of climate scenarios}

A key difference between the climate scenarios, and between different times within each scenario, is the frequency of strong cyclonic storms, which can lead to high sea levels associated with storm surges. The Q0 scenario has the largest number of storm events, characterised by low pressure and high wind speed (Table 1). The variability between years is large, but there seems to be a trend towards fewer storms in the mid- $21^{\text {st }}$ century and then more again towards the end of the century. Q8 starts at a similar level, but storm freqency falls through the century, Q16 shows the fewest storms throughout, with a decrease through the century. The role of multi-decadal variability in these scenarios has not been investigated. A fall in the storm frequency by 2100 is consistent with the results of Sarthi et al. ${ }^{37}$, who used a similar model and the higher emission A2 scenarios. High sea levels can also be associated with persistent strong wind conditions, as can occur during the monsoon, and the 5-day running mean of the northward wind speed was used as a way to identify this kind of event. On this measure the scenarios are again ordered Q0, Q8, Q16, although with a rising trend noticeable in Q16 (Table 1).

A third type of event associated with flooding in the coastal region is high river flows. For all three scenarios there is a rise in the number of high flow days across the century, with the rise occurring earlier for Q0 than Q8 and Q16 but not reaching such high levels (Table 1). These high flow days tend to be associated with a few years where river levels are exceptionally high rather than being spread evenly across the period. It should be noted that the model resolution does not allow for accurate placing of river mouths in the delta area and so spatial aspects 
of river-associated high-water events cannot be modelled accurately.

Table 1 Frequency of flood-associated conditions in the northern Bay of Bengal for three model scenarios. Low p: number of days in a 20 year period with minimum pressure below $965 \mathrm{mb}$. High v: number of days with 5 day mean northern wind speed above $8 \mathrm{~m} / \mathrm{s}$. High riv: number of days with total flow for the delta rivers above $100000 \mathrm{~m}^{3} / \mathrm{s}$. Pressure and wind data are for the region 15.0 to $22.0^{\circ} \mathrm{N}, 83.0$ to $94.0^{\circ} \mathrm{E}$. Time periods are pd: $1991-2010$, mid: 2041-2060, end: 2080-2099.

\begin{tabular}{|c|ccc|ccc|ccc|}
\hline & \multicolumn{10}{|c|}{ Q0 } & \multicolumn{3}{c|}{ Q8 } & & Q16 \\
& pd & mid & end & pd & mid & end & pd & mid & end \\
\hline Low p & 25 & 19 & 29 & 20 & 21 & 16 & 13 & 10 & 1 \\
High v & 58 & 48 & 35 & 23 & 6 & 21 & 4 & 16 & 26 \\
High riv & 24 & 64 & 52 & 43 & 24 & 110 & 28 & 27 & 152 \\
\hline
\end{tabular}

\section{Model domain and validation}

The model system was based on a domain of the Global Coastal Ocean Modelling System ${ }^{13}$, which uses POLCOMS for its hydrodynamic component. The spatial resolution was $0.1^{\circ}$ in longitude and latitude (about $11 \mathrm{~km}$ ) and the domain extended to $200 \mathrm{~km}$ offshore from the shelf break (Fig. 3). There were 40 vertical levels at each grid point, distributed using an scoordinate method. Water depth was constrained to be at least $10 \mathrm{~m}$. The present-day model bathymetry was taken from the GEBCO 1' $1^{\prime}$ dataset $^{38}$. Boundary condition and forcing data is discussed in section 2 .

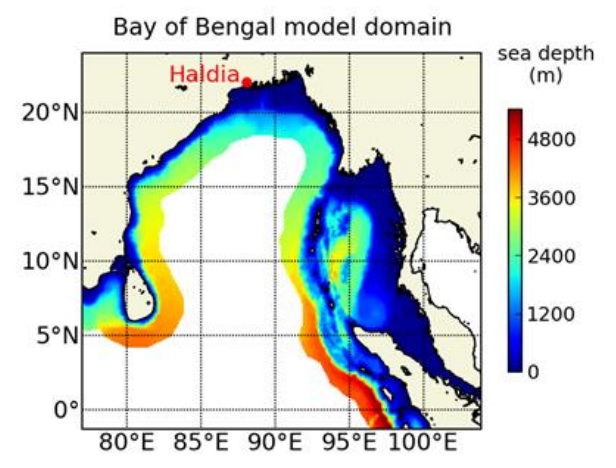

Fig. 3. Domain of the Bay of Bengal model (coloured region). The colours show the model bathymetry. Haldia, West Bengal, is the location of tide gauge data and projections used in this work.

\section{Model approximations and limitations}

The resolution of the model - about $11 \mathrm{~km}$ horizontally, and with a minimum water depth of $10 \mathrm{~m}$ - means that the complex shape of the delta's coastline can only be represented approximately. This will affect the modelled circulation at the coast: in a recent study of sea level rise in the German Bight, Arns et al. ${ }^{39}$ found that changes in tides and non-linear tidesurge interactions were largest in shallow water areas.
In addition, the model domain has a fixed land-sea boundary, so the effect on circulation of the changing shoreline shape is omitted. The same assumption has been made by other authors, e.g. Pickering et al. $^{40}$, Howard et al. ${ }^{41}$, who argued it was a reasonable approximation given the uncertainty over future shoreline position, which depends on submergence, morphodynamics and what sea defences may be put in place. Other authors have presented storm surge models of the Bay of Bengal that do include inundation, e.g, Lewis et al. ${ }^{42}$, Flather ${ }^{43}$ : but these generally aim to model the impact of individual storm events rather than change over a period of several decades.

The relatively coarse resolution and fixed shoreline mean that the specific details of modelled sea level at any one location are unlikely to be accurate. However, the model can still be used to consider the broader picture of regional change.

The amount of sea level rise is assumed to be constant around the model domain. This is a reasonable approximation for the northern region but may be less accurate for the central and southern Bay. IPCC projections suggest variation of up to $0.1 \mathrm{~m}$ over the Bay for the period to 2100, with greater differences in the north-south than east-west direction. The sea level rise applied through the boundary conditions was the same for all three scenarios.

One further limitation should be noted: bias in the modelling of the most extreme cyclone events. In common with other climate models, it is challenging for the regional atmospheric model HadRM3P to simulate the full intensity of tropical cyclones due to its limited spatial resolution, although severe storm-like events do occur within the model outputs. Projected changes in the frequency and intensity of storm events over the modelled period may be reasonable but the intensity of the strongest events is likely to be underestimated ${ }^{44}$. Thus the surge events generated in the POLCOMS model via the atmospheric data from HadRM3P will also be underestimated. There may also be inaccuracies in the location of landfall of the modelled storms: because of the way sea surface temperatures are updated in the RCM it has some inaccuracy in modelling the distribution of cyclone tracks in the Indian Ocean ${ }^{45}$.

\section{Model validation}

POLCOMS has been validated for modelling tide and storm surge in north European seas, e.g. ${ }^{46,47}$. For the current model, outputs from the reanalysis run were compared to records of hourly water level available from the University of Hawaii Sea Level Center ${ }^{48}$ for three coastal tide gauges in the Bangladesh delta (see Fig 5a for locations) and one on the east coast (Cox's Bazaar, $21.45^{\circ} \mathrm{N}, 91.83^{\circ} \mathrm{E}$ ). Table 2 gives four sets of error statistics for the daily maximum high water level: the root mean square error (RMSE), the coefficient of determination $\left(r^{2}\right)$, the index of agreement $(d)^{49}$ and the percentage bias $(\mathrm{PB})^{50}$. Agreement is reasonably good at Hiron Point and Khepupara, 
with high $d$ (perfect fit gives $d=1$ ) and low bias. At Char Changa and Cox's Bazaar the model consistently overestimates the tidal amplitude and so the maximum daily values have a high bias. As discussed above, the model resolution is not high enough to capture the shape of the coastline in detail and so some deviation from observed water levels is to be expected.

Table 2 Error statistics for a comparison of observed and modelled highest daily sea surface elevations at four locations on the Bangladesh coast. See Fig. 5a for the location of the first three points, Cox's Bazaar is on the east coast, at $21.45^{\circ} \mathrm{N}, 91.83^{\circ} \mathrm{E}$

\begin{tabular}{|c|c|c|c|c|c|}
\hline Station & $\begin{array}{c}\text { Comparison } \\
\text { period }\end{array}$ & $\begin{array}{c}\text { RMSE } \\
(\mathrm{m})\end{array}$ & $r^{2}$ & $d$ & PB \\
\hline Hiron Point & $1993-2003$ & 0.20 & 0.76 & 0.92 & 7.72 \\
\hline Khepupara & $1993-2000$ & 0.29 & 0.69 & 0.87 & 11.4 \\
\hline Char Changa & $1993-2000$ & 0.94 & 0.76 & 0.62 & -85.9 \\
\hline Cox's Bazaar & $1993-2006$ & 0.48 & 0.76 & 0.77 & -39.5 \\
\hline
\end{tabular}

Histograms of the highest daily height at Hiron Point and Khepupara show that the spread of the distribution, and hence the range of the observed high water levels, is captured reasonably well (Fig. 4). One feature of the distributions should be noted: the reanalysis-driven model has too few events at very high levels - the distribution lacks the high tail seen in the observations. The reanalysis atmospheric data does not capture the extreme low pressures and high wind speeds associated with cyclonic storms, and so the surge caused by these events is missing from the data. The HadRM3P climate model data used in this study has a higher resolution, approximately $24 \mathrm{~km}$ compared to $80 \mathrm{~m}$ for the ERA Interim reanalysis data, and it does include intense low pressure events. The tail of the distribution for the Q0-driven model is a better match to observation than that for the reanalysis-driven model (Fig. 4).
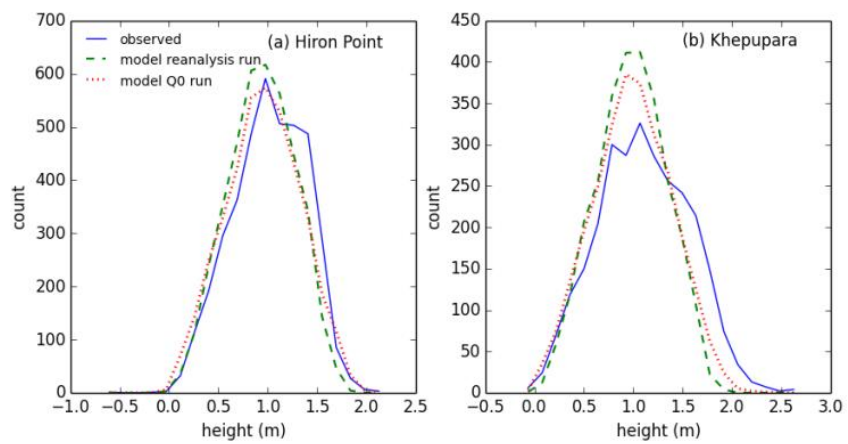

Fig. 4 Distribution of highest daily sea surface heights at two coastal stations. Each plot shows observed data (solid blue line), data from the POLCOMS model forced using reanalysis data (green dashed) and the model with forcing from the QO climate scenario (red dotted).

As one further validation exercise, the observed and modelled hourly time series were analysed to find the tidal constituents, using the analysis package Tappy ${ }^{51}$. The main tidal constituents for three stations are given in Table 3; the observed data at Khepupara had too many gaps for a reliable analysis. As for the daily maximum height, agreement at Hiron Point is better than at Char Changa or Cox's Bazaar - this is probably due to features of the local topography that are not resolved by the model.

Table 3 Amplitudes of the highest tidal constituents at three locations for observed and modelled data, analysis periods as Table 2.

\begin{tabular}{|ccccccccc|}
\hline $\begin{array}{c}\text { Tidal } \\
\text { const- } \\
\text { ituent }\end{array}$ & $\begin{array}{c}\text { Hiron Point } \\
\text { obs }\end{array}$ & model & $\begin{array}{c}\text { Tidal } \\
\text { const- } \\
\text { ituent }\end{array}$ & \multicolumn{2}{c}{$\begin{array}{c}\text { Char Changa } \\
\text { obs }\end{array}$} & $\begin{array}{c}\text { Tidal } \\
\text { model } \\
\text { const- }\end{array}$ & $\begin{array}{c}\text { Cox's Bazaar } \\
\text { obs }\end{array}$ & model \\
ituent & & & & & \\
S2 & 0.82 & 0.72 & M2 & 0.93 & 1.69 & M2 & 0.92 & 1.41 \\
Sa & 0.35 & 0.35 & Sa & 0.57 & 0.29 & Sa & 0.38 & 0.15 \\
N2 & 0.17 & 0.23 & S2 & 0.36 & 0.69 & S2 & 0.35 & 0.61 \\
K1 & 0.13 & 0.16 & MSf & 0.19 & 0.04 & N2 & 0.16 & 0.26 \\
K2 & 0.10 & 0.14 & M2 & 0.17 & 0.29 & MSf & 0.13 & 0.03 \\
O1 & 0.05 & 0.07 & MS4 & 0.11 & 0.11 & K2 & 0.09 & 0.22 \\
Ssa & 0.05 & 0.04 & K2 & 0.08 & 0.30 & O1 & 0.07 & 0.18 \\
nu2 & 0.04 & 0.00 & mu2 & 0.08 & 0.17 & Ssa & 0.07 & 0.06 \\
P1 & 0.04 & 0.04 & L2 & 0.08 & 0.06 & M4 & 0.06 & 0.07 \\
\hline
\end{tabular}

\section{Results and discussion}

Hourly values of sea surface elevation were extracted from the model outputs for a number of points in the delta region (Fig. 5a). The annual mean elevation shows sea level rising in line with the input SLR data (Fig. 5b). The change is fairly consistent for all points, reflecting the assumption of uniform sea level rise built into the model. Note that these values are higher than those in Fig. 1 because subsidence has been added to the model output. There are some differences in elevation between the points, but given the coarse resolution of the model (about $11 \mathrm{~km}$ ), especially in respect to the varying shape of the sea bed, these differences should not be taken as significant; instead the results presented below focus on the variation across the modelled time period. The scatter of points in Fig. 5b gives an indication of the modelled inter-annual variability in sea level. There is an indication of a reduction in variability in midcentury: this is reminiscent of the decadal change in mean sea level variability seen in historic data for the North Atlantic ${ }^{52}$. In this case the change seems to be associated with the frequency of low pressure events (Table 1), which reduces in mid-century for scenario Q0. The Q8 results (not shown) are fairly constant through the century and Q16 shows a decrease in variability; see also Fig. 6..

A sample 5-year hourly elevation series for one point shows how occasional events of unusually high water occur within the regular tidal cycle (Fig. 5c), and events like this occurred throughout the time period. To test whether these events could be storm surges associated with cyclonic storms, the mean daily sea surface elevation for the delta region was compared to the minimum daily pressure in the northern Bay of Bengal. The Spearman correlation between these variables was in the range -0.85 to -0.87 for all three scenarios (using values of elevation from which the trend associated with sea level rise had been removed). In Fig. 6 a plot of mean daily elevation has been highlighted to show days of extremely low pressure: low pressure coincided with many, but not all, the high sea level 
events. Other potential causes of high sea surface elevation include persistent onshore winds and high river levels; for 5day mean wind speed the correlation was 0.67 to 0.77 and for daily river flow it was 0.64 to 0.68 . Consistent with these lower correlations, there were fewer coincidences between extremes in wind speed or river flow and the highest water events (Fig. 6). In particular, high river flows did not seem to be associated with the highest sea surface elevations: this may reflect the lack of resolution of rivers in this model and further work would be needed to judge whether high river flows are actually less important than storm surge.

The vertical spread of the plots in Fig. 6 shows that the Q8 scenario has less variability than Q0, and Q16 least of all. This is in line with the different frequency of storm events in the three scenarios (Table 1) and suggests that moderate as well as extreme storms are most frequent in Q0. In general, the height of the most extreme storms is less far above the background level in the second half of the century than the first. This can also be seen in Fig. 8, which shows the most extreme heights at beginning, mid- and end-century for three sample points.

To explore the changing frequency of high water events, the number of events where sea level rose above a threshold value was calculated, based on the hourly model outputs. Inspection of the data showed that storm events can last up to two days, so a level recurring within two days was counted as a single event. For each climate scenario two thresholds were chosen by examining the data for 1991-2010: the very high threshold was set where two events occurred in that twenty year period, the high threshold where ten events occurred. Both thresholds were set locally, i.e. they vary from point to point. Table 4 has the threshold values for the three points tested, but the sizes should not be taken as more than indicative (see comments on model validation, above). Note that this analysis considers the total water level, with contributions from tides, sea level rise and surge associated with storms or other weather conditions, i.e. the results are treated as a set of possible instances of water level conditions as they might be experienced at a given location over time. This means it offers a way of assessing changing risk of extreme sea levels, but cannot give information about the separate effects of different contributions to that risk. Some comments about the separate changes in tide and surge are given at the end of section 4 .

Table 4 Thresholds for "high" and "very high" events for the three climate scenarios, for three points as shown in Fig. 5a.

\begin{tabular}{|c|ccc|ccc|}
\hline Scenario & \multicolumn{3}{|c|}{ "high" threshold (m) } & \multicolumn{3}{|c|}{ "very high" threshold } \\
& & & & & $(\mathrm{m})$ \\
& Pt 2 & Pt 5 & Pt 7 & Pt 2 & Pt 5 & Pt 7 \\
\hline Q0 & 2.25 & 2.44 & 3.37 & 2.52 & 2.84 & 3.94 \\
Q8 & 2.19 & 2.28 & 3.17 & 2.46 & 2.60 & 3.55 \\
Q16 & 2.07 & 2.17 & 3.10 & 2.34 & 2.67 & 3.51 \\
\hline
\end{tabular}

The frequency of high water events increased for all scenarios at all three points, as expected given the scenario of sea level rise applied (Fig. 7). Scenario Q16 showed the highest number of events even though it was the least stormy (Table 1): as noted above, the thresholds were defined in relation to current conditions and Q16 had the lowest thresholds because it experienced less extreme conditions in the present day period (Table 4). Taken together, the three scenarios illustrate a range of possible futures. Events that occur annually in present-day conditions could be occurring 3-10 times per year by midcentury and 15-40 times per year at the end of the century. What are now decadal events could occur most years by midcentury and 3-15 times per year by end-century (Fig. 7). There is some indication of spatial variation in the data, with point 5 showing a slower increase in very high events but, as previously stated, this should be interpreted with caution for the current model, both because of limited resolution at the coast and because of possible bias in the intensity of cyclones and location of cyclone tracks ${ }^{45}$. (a)

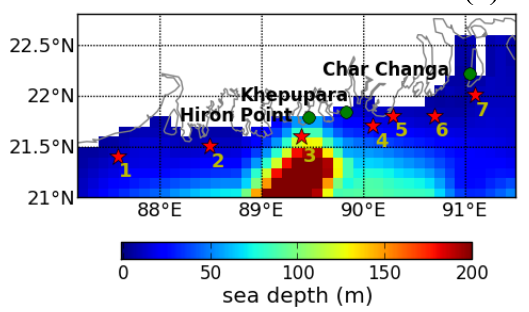

(b)

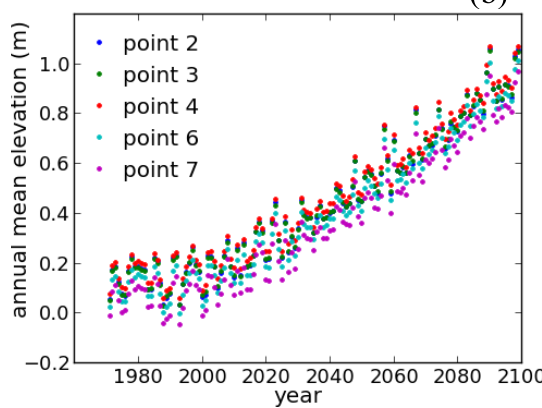

(c)

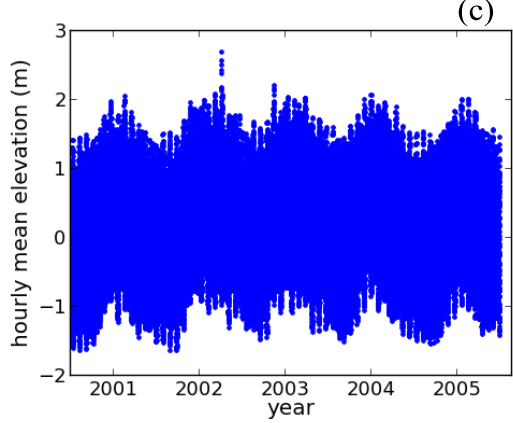

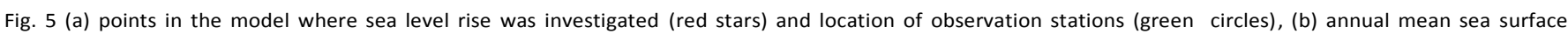

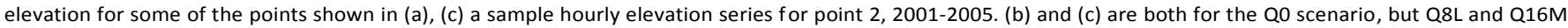
show similar patterns. 
Q0

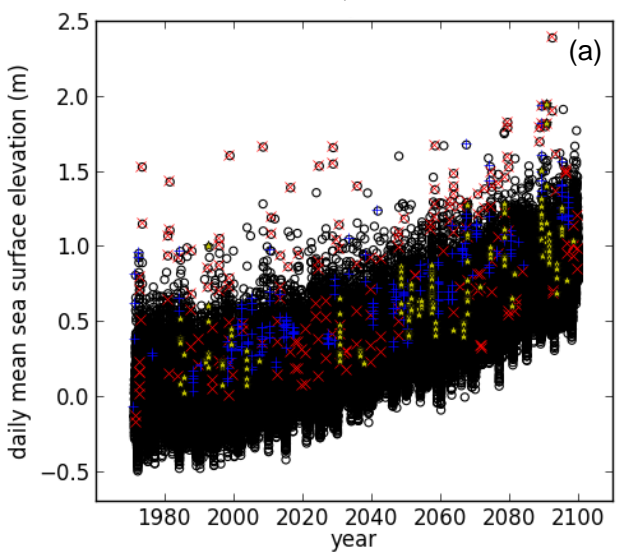

Q8

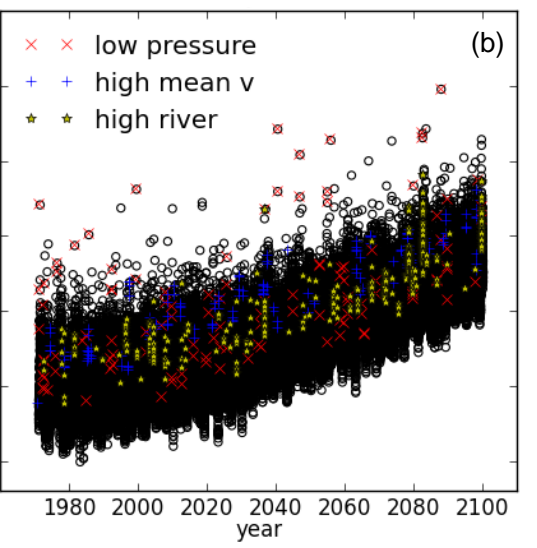

Q16

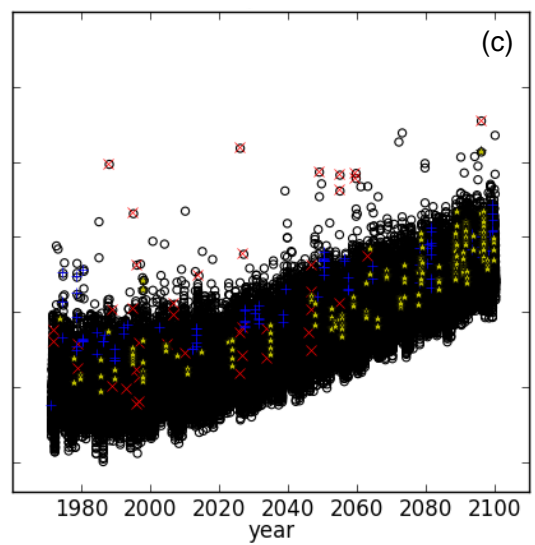

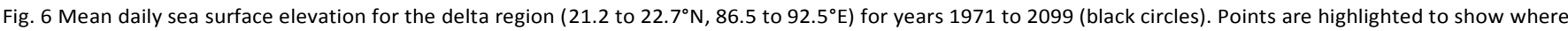

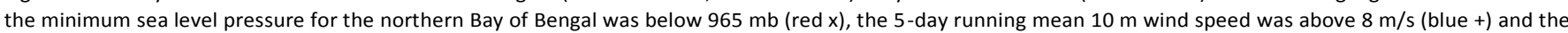
daily total flow for the delta rivers was over $10^{5} \mathrm{~m}^{3} / \mathrm{s}$ (yellow star).
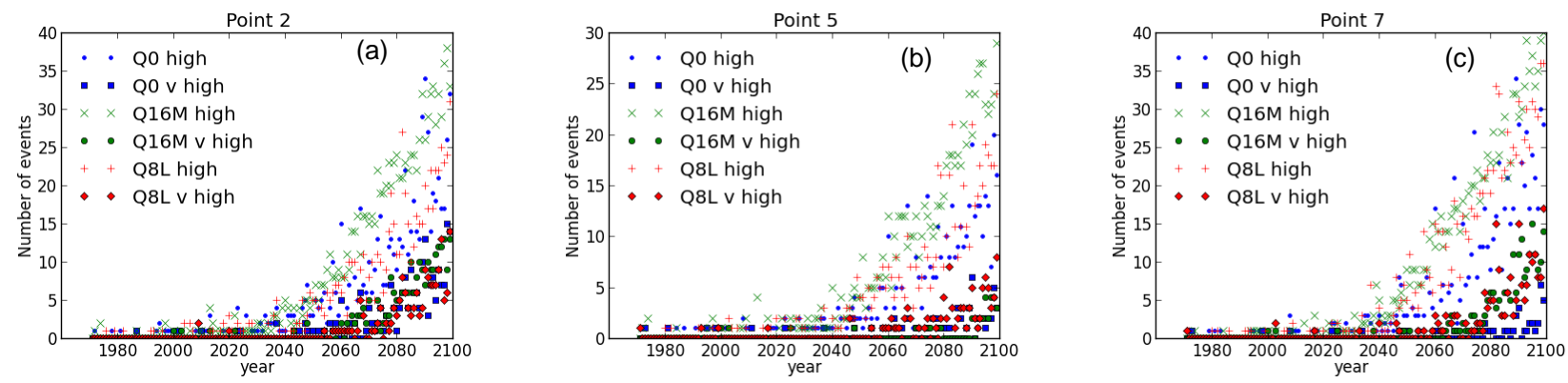

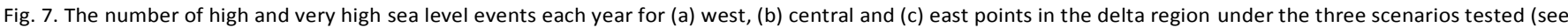

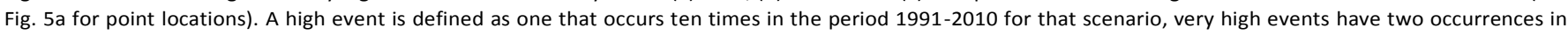
the same period. 

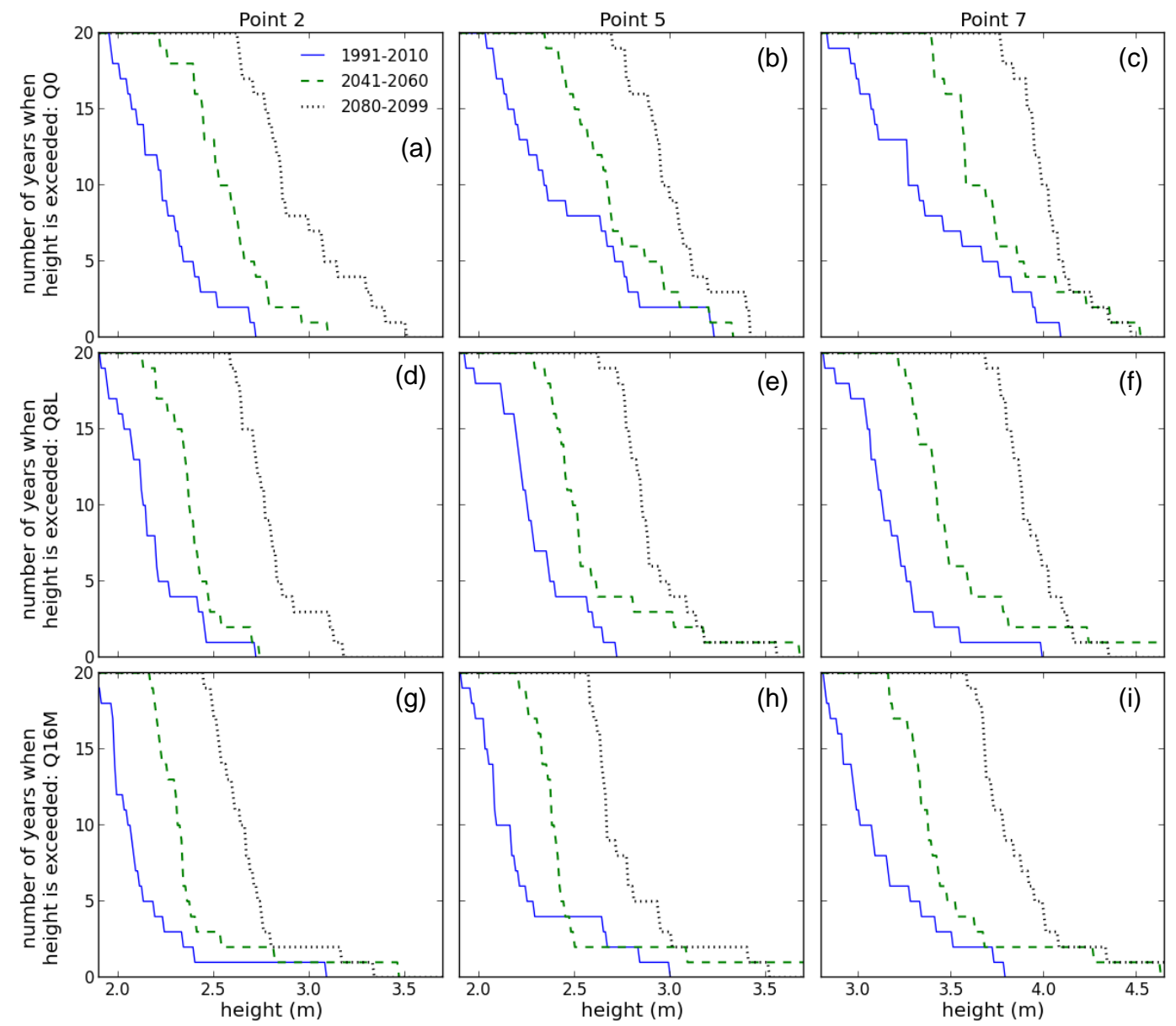

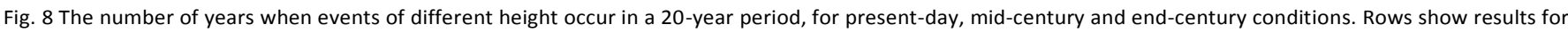
the three scenarios tested, columns show three different points; see Fig. 5a for point locations.

An alternative way of assessing the changing frequency of extreme sea levels is to look at the number of years in a twentyyear period when events of a given height occur (Fig. 8). Sea surface heights which occurred once or twice in the period in present-day conditions, e.g. $2.5 \mathrm{~m}$ for point 2 under scenario Q0, occurred about 10 times in 20 years by mid-century and every year by end century. In some cases, the risk of the most extreme events remained small, but the frequency of slightly lower events still increased sharply (e.g. Fig. $8 \mathrm{~g}$ ). The height of the most extreme events increased in most of the cases tested, usually by about $0.5 \mathrm{~m}$ but up to $1 \mathrm{~m}$. The height of the most extreme event did not always occur at the end of the century, in several cases the mid-century maximum was at least as high (e.g. Fig. 8c,e,h,). However, for the events that occurred 3-5 times in 20 years the water levels were always higher at the end of the century.

\section{Contributions to changing water level from tide and environmental changes}

The total water level is a combination of contributions from the mean sea level, the astronomically-determined tide, the weather-dependent surge and interactions between them ${ }^{39}$. The tidal component was investigated by carrying out tidal analysis on 20-year sections of model output using Tappy ${ }^{51}$; the 20-year period includes a full nodal cycle but is small enough to ensure that the change in mean sea level within the period is small. Results for the annual and semi-annual constituents Sa and Ssa are shown in Fig. 9, for two sample points. These constituents are meteorologically determined and are different for each climate run; the range of amplitudes is another demonstration of the inter-annual variability within the data and there is some indication of variability on a decadal scale. The variation of Sa with air pressure, air temperature and wind conditions was found in observations for North European stations by Plag et al. ${ }^{53}$. In this case it may also be related to the river flow, which has a very strong 12 month cycle. 

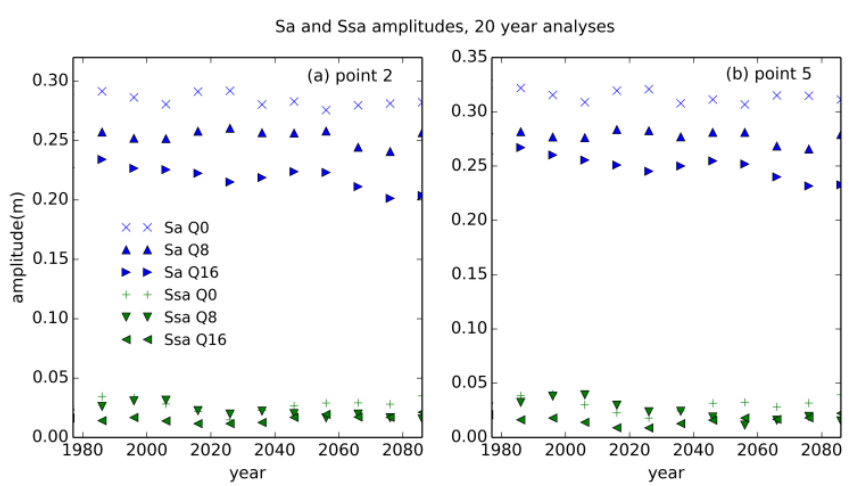

Fig.9 Amplitudes of the Sa and SSa annual and semi-annual tidal constituents at points 2 and 5 for the period 1971-2099, for the three climate scenarios. For all points shown, analysis was carried out on a 20 -year set of modelled sea surface elevations. See Fig. 5 a for location of points.

Change in other major tidal constituents was examined for the mid-century and end-century periods (Fig. 10). The fall in M2 amplitude and the variability of Sa and Ssa has already been seen in Fig. 9. Some constituents change by little (P1, mu2) but many show an increase or decrease compared to present-day values. In some cases the change varies depending on the climate forcing (M4, MS4, MN4); since the background sea level rise and tidal forcing was the same for all the climate runs this indicates the importance of interactions between the tidal and meteorological forcing. Arns et al. ${ }^{39}$, in a study of the German Bight using a high resolution model that allowed inundation, found that tidal constituents were affected both by sea depth and by surge conditions. A similar model for the GBM delta region would be needed to assess the size of the tidal changes, but the work presented here gives an indication that changes in local tides are likely to result from sea level rise.

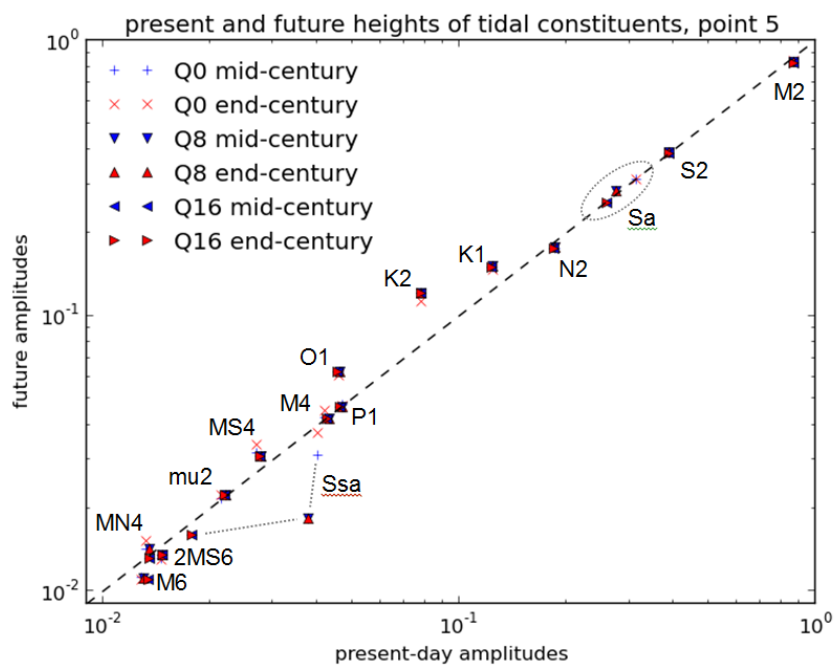

Fig. 10. Comparison of amplitudes of the 15 largest tidal constituents for present-day and future conditions, for three climate scenarios. All data is for point 5 (see Fig. 5a for location)
Residuals were calculated by using the tidal analysis to generate the tidal component and subtract this from the overall sea surface elevation. A sample plot is shown in Fig. 11; surge events stand out clearly.

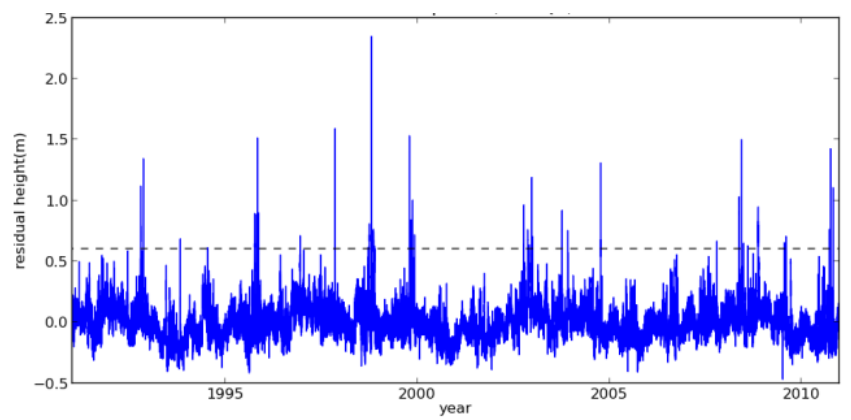

Fig. 11 Residual height above mean sea level for point 5, 1991-2010, using climate run Q0. See Fig. 5a for location of this point.

The number of storm surge events occurring in these residuals is given in Table 5, for three time periods and three locations. These data are not simply related to the frequency of extreme meteorological events shown in Table 1, again suggesting the importance of interaction between tide and surge in determining the overall sea surface height. Values for point 7 seem to rise strongly at the end of the century, but surge events are less well defined here, perhaps because of its location near the mouth of the river channel, so the values may be less reliable than for points 2 and 5 .

Table 5 Number of events where the non-tidal residual exceeds a threshold at three delta points, for three 20 year periods. Present day $(\mathrm{pd})=1991-2010$, mid-century $=2041-2060$, end-century $=2080-2099$. The threshold was $0.6 \mathrm{~m}$ for points 2 and 5, $0.8 \mathrm{~m}$ for point 7 . For the location of points see Fig.5a.

\begin{tabular}{|c|ccc|ccc|ccc|}
\hline Point & \multicolumn{3}{|c|}{ Q0 } & \multicolumn{3}{c|}{ Q8 } & \multicolumn{3}{c|}{$\begin{array}{c}\text { Q16 } \\
\text { mid }\end{array}$} \\
& pd & mid & end & pd & mid & end & pd & mid \\
\hline 2 & 22 & 24 & 33 & 13 & 10 & 15 & 15 & 7 & 8 \\
5 & 38 & 31 & 44 & 26 & 19 & 20 & 19 & 12 & 10 \\
7 & 13 & 33 & 68 & 8 & 27 & 63 & 11 & 23 & 51 \\
\hline
\end{tabular}

\section{Conclusions}

We present projections of sea level for the GBM delta in the $21^{\text {st }}$ century, based on model runs with sea level rise and three alternative scenarios of climate change. The general trend is of a gradually increased likelihood of high water events through the 21 st century, with the frequency of extreme events increasing greatly in the second half of the century. Instances of more extreme coastal water level were generally associated with conditions of low atmospheric pressure and some with persistent onshore winds; the model was not able to resolve events associated with high river flow levels. 
The three climate scenarios have the same underlying projection of sea level rise, but different levels of current and future storms and so give a range of possible future event frequency. Events that occur about once a decade in presentday conditions occurred in most years by mid-century and 3-15 times per year by end-century. In several of the cases tested the height of the most extreme events was as great in the middle of the century as at the end, but events close to this maximum height were more common at the end of the century. Thus the most extreme events could be summarised as increasing in height in the first part of the century and increasing in frequency in the second half.

Tidal analysis suggests that sea level rise will give a change in tidal constituents and that local sea levels depend on the interaction between tide and surge..

The modelled scenarios described in this paper can only illustrate some potential futures for the increasing frequency of extreme sea levels in the GBM delta and they cannot give an estimate of the probability of different levels of risk - further modelling studies would be needed to provide that. The current work does not sample a range of outcomes, including forcing by models other than the three considered. It also omits the strongest storm surges, as the climate forcing data does not model the most intense tropical cyclones. A higher resolution model is needed to capture local variation in sea level heights for this complex shoreline, and wave modelling should be included to estimate full sea height at the shoreline.

In spite of these limitations, the modelled scenarios provide a case study of how sea level rise and other effects of climate change may combine to produce greatly increased threat to life and property by the end of this century. The increase in extreme events shown here could be reduced if efforts to cut down global emissions of greenhouse gases are successful. However, in the absence of climate mitigation appropriate coastal management and/or large-scale migration from the delta will be needed in response to the increasing frequency of extreme sea levels. Hence, sea-level rise is a significant threat to the development of the delta.

\section{Acknowledgements}

This work 'Assessing health, livelihoods, ecosystem services and poverty alleviation in populous deltas', project number NEJ002755-1, was funded with support from the Ecosystem Services for Poverty Alleviation (ESPA) programme. The ESPA programme is funded by the Department for International Development (DFID), the Economic and Social Research Council (ESRC) and the Natural Environment Research Council (NERC). The authors would like to thank Riccardo Torres and Munsur Rahman for useful comments. We also thank the two anonymous reviewers whose comments and suggestions greatly improved the quality of the paper.

\section{Notes and references}

${ }^{a}$ Plymouth Marine Laboratory, Prospect Place, The Hoe, Plymouth PL1 3DH, UK suka@pml.ac.uk.

${ }^{b}$ Met Office Hadley Centre, FitzRoy Road, Exeter, EX1 3PB, UK.

${ }^{c}$ National Oceanography Centre, Joseph Proudman building, 6 Brownlow Street, Liverpool L3 5DA, UK.

$d$ Engineering and the Environment, University of Southampton, Highfield, Southampton, SO17 1BJ, UK

${ }^{e}$ Institute of Water and Flood Management, Bangladesh University of Engineering and Technology, Dhaka-1000, Bangladesh

1 J. Milliman, J. M. Broadus and F. Gable, Ambio, 1989, 18, 340-345.

2 R. A. Warrick, A. H. Bhuiya and M. Q. Mirza, Climate Change and Sea-level Rise: the Case of the Coast, Bangladesh Unnayan Parishad (BUP), Dhaka, 1993.

3 J. P. Ericson, C. J. Vörösmarty, S. L. Dingman, L. G. Ward and M. Meybeck, Glob. Planet. Change, 2006, 50, 63-82.

4 J. A. Church, P. U. Clark, A. Cazenave, J. M. Gregory, S. Jevrejeva, A. Levermann, M. A. Merrifield, G. A. Milne, R. S. Nerem, P. D. Nunn, A. J. Payne, W. T. Pfeffer, D. Stammer and A. S. Unnikrishnan, in Climate Change 2013: The Physical Science Basis. Contribution of Working Group I to the Fifth Assessment Report of the Intergovernmental Panel on Climate Change, eds. T. F. Stocker, D. Qin, G.-K. Plattner, M. Tignor, S. K. Allen, J. Boschung, A. Nauels, Y. Xia, V. Bex and P. M. Midgley, Cambridge University Press, Cambridge, United Kingdom and New York, NY, USA, 2013, pp. 1137-1216.

5 V. Mikhailov and M. Dotsenko, Water Resour., 2007, 34, 385-400.

6 S. A. Higgins, I. Overeem, M. S. Steckler, J. P. M. Syvitski, L. Seeber and S. H. Akhter, J. Geophys. Res. Earth Surf., 2014, 119, 1768-1781.

7 J. P. M. Syvitski, A. J. Kettner, I. Overeem, E. W. H. Hutton, M. T. Hannon, G. R. Brakenridge, J. Day, C. Vörösmarty, Y. Saito, L. Giosan and R. J. Nicholls, Nat. Geosci., 2009, 2, 681-686.

8 O. Singh, T. M. A. Khan and S. Rahman, The Vulnerability Assessment of the SAARC Coastal Region Due to Sea Level Rise, Bangladesh Case, SAARC Meteorological Research Centre (SMRC), 2000.

9 A. S. Unnikrishnan and D. Shankar, Glob. Planet. Change, 2007, 57, 301-307.

10 S. L. Goodbred Jr. and S. A. Kuehl, Sediment. Geol., 2000, 133, $227-$ 248.

11 M. S. Steckler, S. L. Nooner, S. H. Akhter, S. K. Chowdhury, S. Bettadpur, L. Seeber and M. G. Kogan, J. Geophys. Res. Solid Earth, 2010, 115, B08407.

12 H. Brammer, Clim. Risk Manag., 2014, 1, 51-62.

13 J. Holt, J. Harle, R. Proctor, S. Michel, M. Ashworth, C. Batstone, I. Allen, R. Holmes, T. Smyth, K. Haines, D. Bretherton and G. Smith, Philos. Trans. R. Soc. Math. Phys. Eng. Sci., 2009, 367, 939-951.

14 J. Caesar, T. Janes, A. Lindsay and B. Bhaskaran, Environ. Sci. Process. Impacts, 2015,17,1047-1056.

15 R. E. Kopp, R. M. Horton, C. M. Little, J. X. Mitrovica, M. Oppenheimer, D. J. Rasmussen, B. H. Strauss and C. Tebaldi, Earths Future, 2014, 2, 383-406.

16 M. F. Karim and N. Mimura, Glob. Environ. Change, 2008, 18, 490500. 
17 J. T. Holt and I. D. James, J. Geophys. Res., 2001, 106, 1401514,034 .

18 S. M. Griffies and R. J. Greatbatch, Ocean Model., 2012, 51, 37-72.

19 K. E. Taylor, R. J. Stouffer and G. A. Meehl, Bull. Am. Meteorol. Soc., 2011, 93, 485-498.

20 IPCC, Climate Change 2007: The Physical Science Basis. Contribution of Working Group I to the Fourth Assessment Report of the Intergovernmental Panel on Climate Change, Cambridge University Press, Cambridge, United Kingdom and New York, NY, USA, 2007.

21 M. Perrette, F. Landerer, R. Riva, K. Frieler and M. Meinshausen, Earth Syst Dynam, 2013, 4, 11-29.

22 A. Levermann, R. Winkelmann, S. Nowicki, J. L. Fastook, K. Frieler, R. Greve, H. H. Hellmer, M. A. Martin, M. Meinshausen, M. Mengel, A. J. Payne, D. Pollard, T. Sato, R. Timmermann, W. L. Wang and R. A. Bindschadler, Earth Syst Dynam, 2014, 5, 271-293.

23 S. Jevrejeva, A. Grinsted and J. C. Moore, Environ. Res. Lett., 2014, 9, 104008 .

24 S. Brown and R.J. Nicholls, Science of The Total Environment, 2015, 362-374.

25 G. D. Egbert and S. Y. Erofeeva, J. Atmospheric Ocean. Technol., 2002, 19, 183-204.

26 C. Gordon, C. Cooper, C. A. Senior, H. Banks, J. M. Gregory, T. C. Johns, J. F. B. Mitchell and R. A. Wood, Clim. Dyn., 2000, 16, 147168.

27 J. M. Murphy, B. B. B. Booth, M. Collins, G. R. Harris, D. M. H. Sexton and M. J. Webb, Philos. Trans. R. Soc. Math. Phys. Eng. Sci., 2007, 365, 1993-2028.

28 M. Collins, B. B. B. Booth, G. R. Harris, J. M. Murphy, D. M. H. Sexton and M. J. Webb, Clim. Dyn., 2006, 27, 127-147.

29 M. Collins, B. B. B. Booth, B. Bhaskaran, G. R. Harris, J. M. Murphy, D. M. H. Sexton and M. J. Webb, Clim. Dyn., 2011, 36, 1737-1766.

30 R. G. Jones, M. Noguer, D. C. Hassell, D. Hudson, S. S. Wilson, G. J. Jenkins and J. F. B. Mitchell, Generating high resolution climate change scenarios using PRECIS, Met Office Hadley Centre, Exeter, UK, 2004.

31 D. P. Dee, S. M. Uppala, A. J. Simmons, P. Berrisford, P. Poli, S. Kobayashi, U. Andrae, M. A. Balmaseda, G. Balsamo, P. Bauer, P. Bechtold, A. C. M. Beljaars, L. van de Berg, J. Bidlot, N. Bormann, C. Delsol, R. Dragani, M. Fuentes, A. J. Geer, L. Haimberger, S. B. Healy, H. Hersbach, E. V. Hólm, L. Isaksen, P. Kållberg, M. Köhler, M. Matricardi, A. P. McNally, B. M. Monge-Sanz, J.-J. Morcrette, B.-K. Park, C. Peubey, P. de Rosnay, C. Tavolato, J.-N. Thépaut and F. Vitart, Q. J. R. Meteorol. Soc., 2011, 137, 553-597.

32 N. Ferry, L. Parent, G. Garric, M. Drevillon, C. Desportes, C. Bricaud and F. Hernandez, Scientific Validation Report (ScVR) for Reprocessed Analysis and Reanalysis. MyOcean project report, MYO-WP04-SCCV-rea-MERCATOR-V1.0, Toulouse, France, 2012.

33 P. G. Whitehead, S. Sarkar, L. Jin, M. N. Futter, J. Caesar, E. Barbour, D. Butterfield, R. Sinha, R. Nicholls, C. Hutton and H. D. Leckie, Environ. Sci. Process. Impacts, 2015,17,1082-1097.

34 P. G. Whitehead, E. Barbour, M. N. Futter, S. Sarkar, H. Rodda, J. Caesar, D. Butterfield, L. Jin, R. Sinha, R. Nicholls and M. Salehin, Environ. Sci. Process. Impacts, 2015,17,1057-1069.
35 B. M. Fekete, C. J. Vörösmarty and W. Grabs, Glob. Biogeochem. Cycles, 2002, 16, 15-1-15-10.

36 A. Dai, T. Qian, K. E. Trenberth and J. D. Milliman, J. Clim., 2009, 22, 2773-2792.

37 P. P. Sarthi, A. Agrawal and A. Rana, Int. J. Climatol., 2014,7, 12671277 .

38 GEBCO, http://www.gebco.net/ .

39 A. Arns, T. Wahl, S. Dangendorf and J. Jensen, Coast. Eng., 2015, 96, 118-131.

40 M. D. Pickering, N. C. Wells, K. J. Horsburgh and J. A. M. Green, Cont. Shelf Res., 2012, 35, 1-15.

41 T. Howard, J. Lowe and K. Horsburgh, J. Clim., 2010, 23, 62346247.

42 M. Lewis, P. Bates, K. Horsburgh, J. Neal and G. Schumann, Q. J. R. Meteorol. Soc., 2013, 139, 358-369.

43 R. A. Flather, J. Phys. Oceanogr., 1994, 24, 172-190.

44 G. Redmond, K. I. Hodges, C. McSweeney, R. Jones and D. Hein, Submitt. Clim. Dyn., 2014, doi 10.1007/s00382-014-2450-8.

45 F. Farquharson, F. Fung, J. U. Chowdhury, A. Hassan, K. Horsburgh and J. Lowe, Impact of CLimate And Sea Level Change in part of the Indian Sub-Continent, (CLASIC). Final Report, Department for International Development, 2007.

46 J. M. Brown, A. J. Souza and J. Wolf, Ocean Model., 2010, 33, 118 128.

47 J. T. Holt, J. I. Allen, R. Proctor and F. Gilbert, J. Mar. Syst., 2005, 57, 167-188.

48. University of Hawaii Sea Level Center, http://uhslc.soest.hawaii.edu/, accessed 8 December 2014.

49 P. Krause, D. P. Boyle and F. Bäse, Adv Geosci, 2005, 5, 89-97.

50 J. I. Allen, J. T. Holt, J. Blackford and R. Proctor, J. Mar. Syst., 2007, 68, 381-404.

51. Tidal Analysis Program in Python, http://sourceforge.net/p/tappy/wiki/Main_Page/

52 S. Dangendorf, F. M. Calafat, A. Arns, T. Wahl, I. D. Haigh and J. Jensen, J. Geophys. Res. Oceans, 2014, 119, 6820-6841.

53 H.-P. Plag and M. N. Tsimplis, Glob. Planet. Change, 1999, 20, 173203. 